\title{
Comparative Study of Minimalist Art and Chinese Traditional Ink Painting
}

\author{
Ai Cheng \\ College of Landscape Architecture \\ Sichuan Agricultural University \\ Chengdu, China 611130
}

\author{
Qing Wu \\ College of Landscape Architecture \\ Sichuan Agricultural University \\ Chengdu, China 611130
}

Xinyue Liu

College of Landscape Architecture

Sichuan Agricultural University

Chengdu, China 611130

\section{Miao Tan}

College of Landscape Architecture

Sichuan Agricultural University

Chengdu, China 611130

\author{
Xiaomin Chen \\ College of Landscape Architecture \\ Sichuan Agricultural University \\ Chengdu, China 611130 \\ Yimei Feng \\ College of Landscape Architecture \\ Sichuan Agricultural University \\ Chengdu, China 611130 \\ Xiaofang $\mathrm{Yu}^{*}$ \\ College of Landscape Architecture \\ Sichuan Agricultural University \\ Chengdu, China 611130
}

\begin{abstract}
The Minimalism, as the most important and most characteristic school of art, comes of painting, and later developed to the fields of sculpture, design, music, literature etc. All kinds of Western art genres are still dominant in the modern arts of China. We blindly learn from the West, and adore the West. In view of this the paper has comprehensively discussed and analyzed the correlations and similarities between the Minimalism and Chinese traditional ink painting through literature research, case analysis, comprehensive analysis real contrast and other methods in order to find the balance point. First, the colors they use are single and concise; the ink painting mainly uses black and white, while the Minimalism painting is not limited to black and white. Second, the brushwork of them is simplified and superb. A few strokes express infinite connotation. Third, be fond of leaving blank in space layout. It gives people infinite imagination and leads a person to endless aftertastes. Forth, both of them attach importance to the creation of artistic conception.
\end{abstract}

Keywords-minimalism; China traditional ink painting; color; brushwork; space layout

\section{INTRODUCTION}

From the rise of Modernism to its prosperity, the Minimalist art in many art schools has always been a unique artistic genre, and occupied a leading position in the art circles at that time. The theoretical concept of Minimalist art has penetrated into various fields, including the art fields of painting and sculpture art, and the design industry of industrial design and architectural landscape, which has a profound and revolutionary impact.

As the birthplace of the four civilizations, China, in the long history river, has gave birth to a brilliant and broad culture. Among them, Confucianism, Buddhism, Taoism and other religious theories are "roots" of Chinese culture, and they have played a leading role in the formation of China's social ideology, artistic aesthetic concepts, traditional customs and culture. Under the influence of these thoughts, China also produced a number of distinctive art forms, such as black and white ink painting, elegant and simple porcelain of the Song Dynasty and Guqin music integrating emotion into rhyme. These classical arts contain rich cultural deposits, and they are the treasure of China and the world. Even in modern times, some ancient artistic techniques and aesthetic tastes and philosophy are very worth of learning. Behind the prosperous society and developed civilization, there are many correlations and similarities between the Eastern and Western arts and cultures. The paper will analyze the characteristics of art techniques of the international popular Minimalism and Chinese traditional ink painting and find their similarities. 


\section{The ORIGIN AND DEFINITION OF The MinimALiSM}

\section{A. The Origin of the Minimalism}

The name of Minimalism wasn't defined by the artists. It was generated in the arguments of the theory circle when it gradually stood out conspicuously and emerged frequently. The main cause of it in art field was to fight against the artistic ideological trend of Abstract Expressionism rising in the art circle of New York, the United States, in the middle of the last century. The representative was Jackson Pollock. He often put the canvas on the floor and painted with sticks dipped in paint. He made paint flowing on the canvas at will and then gave these canvases with abstract titles. Thus, we can see that Abstract Expressionism, especially his works, embodied the mania, anxiety and worry [1] of American intellectual circle in the highly industrialized society.

A group of young artists tried to escape from this confusion, and tried to use clear, pure, clean lines instead of disorderly, bold abstract expressionism, and use concise style to return the nature of original objective things [2]. This is the "Minimalism" after Abstract Expressionism.

Minimalism was originated from the exhibition of "American Abstract Expressionists and Imagists" in New York in 1961. After exhibition of works, one style aroused ferociously discussion of critics and scholars. As of this style, artists accurately sketch the edge of large area of color block and define the range of the blocks, so that the painting is as of one unit and limited into two or three colors. This style dramatically expresses independent and concise composition elements. The critics and scholars gave this painting style with large area of blank on canvas many names, and the Minimalist Art was first put forward by Critic and Philosopher Richard Wollheim after discussion. Later it was evolved into the Minimalism which has been widely used in the art circle [3].

\section{B. The Minimalism and Painting}

The Minimalist painting was greatly affected by three theories, Malevich's Suprematism, Kandinsky's Expressionism and Mondrian's Neoplasticism "Fig. 1". Suprematism advocates plane-geometrical, simple expression forms. It mainly is of large-sized color paintings. Kandinsky's "Expressionism has a great influence on Minimalist Artist Barnett Newman and Mark Rothko. It pursues to use a universal but not individual art form, eliminate image implication, and use neutralized lines and colors to get pure shape. Mondrian's Neoplasticism stresses the objective existence of modeling. The painting ideology of Mondrian indicated the development direction of Minimalist paintings and produced a direct and positive influence on it. It suggested that geometry character and inhibition expression is the shortcut of the Minimalism, which can be clearly reflected in the representative works of Minimalism [4].

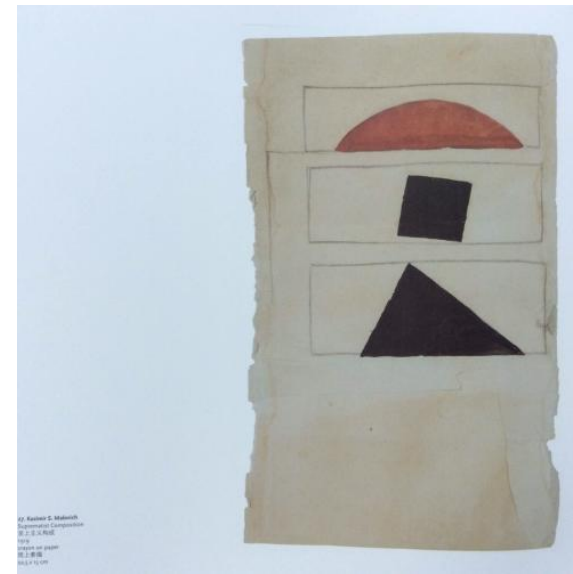

Fig. 1. Kazimier S. Malevich's Supremacist Composition.

Artists of the Minimalist art style adhere to feeling and creating with means and methods as few as possible. They eliminate all redundant and useless elements, and objectively and rationally reflect the nature and principle of things in a concise form [5]. After artists' exploration and efforts, eventually a number of representative Minimalist painters emerged, such as Barnet Newman, Ad Reinhardt, David Smith, Frank Stella and Agnes Martin. Newman is a recognized representative of the Minimalist art.

Newman (1905 1970) was an American painter. His works have the characteristics of large size, almost no texture of the canvas, smooth and clean picture, and strong color contrast. His representative works is one or more vertical lines cutting through the whole picture, which breaks the composition of single color block "Fig. 2". As Critic John Belo said: "the least element in the Minimalist art is means, rather than the art in the works" [6], which is also an accurate summary on Newman's works.

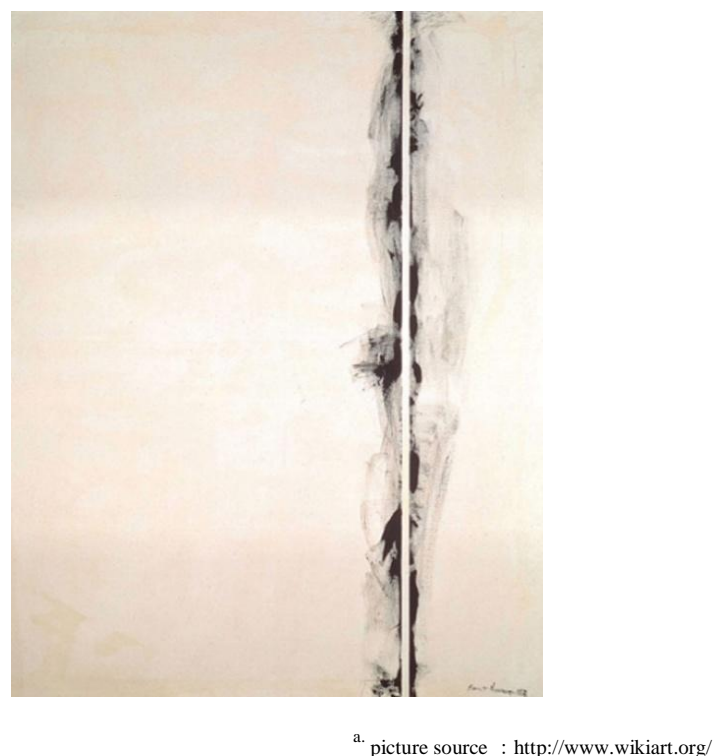

Fig. 2. Barnett Newman's First Station. 


\section{Minimalist Concept}

Minimalism is not now the known Minimalism. In fact, it refers to the last school - Minimalist Art in western modernism in the United States at the beginning of 1960s. It reduced painting and sculpture to their nature, and a "pure abstract" [7]. It goes toward the opposite side of Abstract Expressionism, plays it to the extreme and takes the return of the original nature or form of objects as expression mode. The Minimalism pursues simplicity and supreme. It gives people a concise and clean feeling. The taste and thought are elegant, and the form of expression is deep and rich [8].

\section{The History AND DEFINITION OF CHINESE INK PAINTING}

\section{A. The Development History of Chinese Ink Painting}

China is one of the four ancient civilizations in the world. Our ancestors have created a brilliant culture in the vast land of China. As a part of this splendid culture, Chinese ink painting is the essence of Chinese paintings. For thousands of years, every nation, school of painting, style, and expression techniques constantly evolved and improved with the change of times, and has formed art forms of unique artistic styles with national characteristics, which is second to none in the East and even in the art history of the world.

Chinese ink painting was started in the Tang Dynasty. In the Note Methods, Jing Hao (about $850 \sim$ unknown) recorded: "since ancient times people could apply colors according their categories. But the ink painting was rose in the Tang Dynasty." It is thus clear that the painting at earlier times in China mainly is the application of colors. In Six Painting Principles, Xie He (479 502) of the Southern Qi Dynasty said: "there are six painting principles. One is to use vivid artistic conception. Two is to use hard brushwork. Three is to paint according the image of object. Four is to apply colors according their categories. Five is to arrange its layout. Six is to imitate its shape." In early times, Chinese painters were particular about "painting according the image of object" and "the application of colors according to their categories". They often used lines to sketch the outline and then applied colors. They pursued realism.

Up to the Tang Dynasty, Wang Wei and Wu Daozi and other artists led the formal development of ink painting. At that time, the prosperity of Zen had impacted the Confucian norms of Chinese culture for a long time. Scholars and officialdom emphasized artistic conception and charm in freehand-sketch ink painting, which broke the narrow situation in the past. Thus, it gradually was sought after. In Poet of Mountain and Water, Wang Wei wrote: "the ink painting is the most elegant one in paintings" [9]. It shows that the ink painting had a high position in the Tang Dynasty. This period became the most glorious term for freehand-sketch ink painting. The Ming and Qing Dynasties, and even our modern times have been affected by that period.

\section{B. The Definition of Chinese Traditional Ink Painting}

Ink painting is a unique form of Chinese traditional painting. It uses a single color to depict the real image of object. It is a special creation [10]. As for the definition of "ink painting", the Origins of Words and Phases explains: "a painting only use ink and water without using any colors[11]." The Chinese Art Dictionary says: "it is one kind of Chinese painting. It only uses water and ink. It has three basic factors: pure, symbolic and natural characters. According to legend, it was started from the Tang Dynasty, became mature in the Five Dynasties and prosperous in the Song Dynasty[12]." It should be clarified that "ink and water" is different from "ink painting". "Ink and water" is a morpheme. "Ink painting" is a kind of painting, which is widely used in modern times as a noun.

"Ink painting" first emphasizes precise brushwork. Painters need to select techniques for applying lines, ink and rendering according to painting object and theme in order to complete the form of picture image and build artistic conception. The main color in painting is black, which is produced by "ink". Paint mainly with ink and supplement with colors. Even if use other colors, they only fill the shortage of ink. And the use of colors is required not to interfere with ink. It stresses the dominant position of ink [13].

\section{InK PAINTING AND Minimalist ART}

Chinese ink painting is an art form started from the Tang Dynasty. It has a history of more than 1,500 years and a profound culture deposit. The Minimalism is the last genre of Modernism emerging in 1950s. The two art forms are more than 1,000 years apart, with different origins and cultural backgrounds. But they were similar in aesthetic taste and artistic techniques.

\section{A. Colors}

The prominent characteristics of Chinese ink painting is the application of only black and white colors in painting. It stresses "to color with non-color[14]", and to render the natural beauty of worldly things with plain ink. This is mainly influenced by the philosophy of Taoism. Taoism considers Tao as the original chaos. The characteristics of Tao are natural, plain and doing-nothing. They think plainness and pureness are great beauty. Lao Tzu said: "the five colors make our eyes blind." Chuang Tzu said: "the five colors disturb our eye and make our eyes vague." Taoists thought colors confuse the eyes of people and disturb our judgment with surface phenomena, and we couldn't feel the natural beauty of worldly things. So, Taoists attached great importance to black and white, and regarded the two colors connected with the nature of the universe. Chinese ink painting completely practices this opinion. It paints with thick, thin, dry and wet brushwork on white paper, sketches the grain of object, dots and renders. Taoist thought the highest state of art were that "the acme of gorgeousness is plain", and "the extreme adornment returns to the origin of plainness". In the Famous Paintings in All Ages, Zhang Yanyuan $(815$ 907) also said that "the changes of ink produce rich sense of color, which make the painting lifelike and reflect the image of object vividly".

The Minimalist artists were not limited to the black and white colors in creation. They stressed to use highly pure and saturated colors. Many Minimalist works are of two or three or 
less colors. They thought pure and concise colors could highlight design itself. Just as Art Critic Robert Hughes described the painting of Roscoe in the church of Rice University: "... these huge and hazy paintings are almost in single color... with no theme or shape, no internal relationship, they show themselves to an astonishing degree. The whole world flowed from them, and left only an empty [15]."

The pursuits of colors in Chinese ink painting and Minimalist art are to reflect the nature of things. The differences are that ink painting pursues the nature of the universe truth and gives it with the symbolic meaning of metaphysics, and the Minimalism reflects the nature of thing itself.

\section{B. Strokes}

Influenced by the traditional philosophy of harmony between heaven and man, since the Song Dynasty, Chinese ink painting began to pursue the art characteristic of simplicity. In the Stories of Paintings, Guo Ruoxu said: "the simpler the strokes, the greater the charm; the simpler the scenery the longer the implied meaning[16]." "Simplicity" in ink painting is not to be generally simple or omitted, but to recover one's original simplicity and pursue the "simplicity" of the nature. Artists thought that no matter how complicated the surfaces of worldly things, such as flowers, birds, mountain and water, grass and stone, are, how exquisite their structure are, the "nature" could be reflected in the painting through accepting and rejection. Here, the nature is closely related to artists' feelings, thoughts, character and temperament. So, to meet the requirement of "simplicity" in ink painting, artists should have skillful techniques and deep humanistic feelings. Painter of the Southern Song Dynasty Liang Kai was famous by his concise ink paintings. He simplified ink strokes to the minimum, but he could grasp the connotation of the object. His representative works Taibai Xingyin Tu use only a few strokes, but sketches out the expression of the poet who is thinking over words vividly, without any artificial sense "Fig. 3". It is thus evident that Chinese ink painting pays more attention to charm, feeling and thought reflected by the painting, and stresses simplicity in stroke and brushwork, and eliminates unwanted details, which is the reflection of ancient artists' thoughts to pursue the nature and not to be confused by the surface of things.

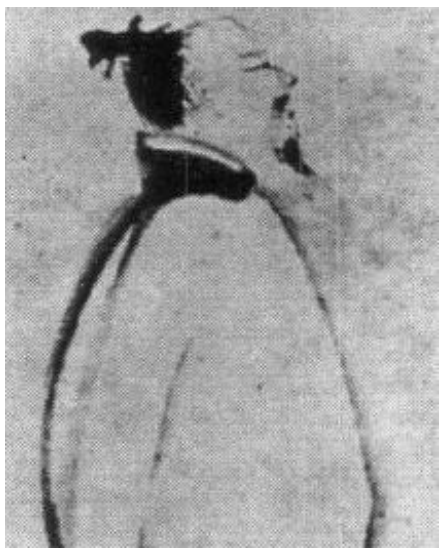

Fig. 3. Taibai Xingyin Tu
The pursuit of "simplicity" in the Minimalism is also to the extreme. According Marcel Duchamp's principle of "little, less, least", the Minimalist art eliminates anything outside art media and pursues complete pureness and completeness to realize the most basic form, order and structure. It advocates analyzing design object, eliminating all additional details and only retaining the key elements. It reflects the important characteristics of the object with the least elements. In this aspect, the Minimalist art is consistent with Chinese ink painting. The West is influenced by the ideology of natural science, and most of western artists simplify things into geometry or straight lines. However, Chinese artists, under the influence of the thought of "to be natural is the nature", mainly use natural curves to depict the object in ink painting. Therefore, both arts use concise artistic techniques to explore the nature.

\section{Space Layout}

Chinese ink painting has its own unique characteristics in space layout. It has a strong philosophical meaning. It is linked with the way of thinking formed by thousands of years of cultural accumulation in China. Since ancient times, China has embraced the world concept of "harmony between heaven and man", which holds that "the law of heaven and the law of man is one thing; things of man and things in nature are an organic whole [17]." It stressed the importance of spirit. So, ink painting pays more attention to the expression of artist's subjective thoughts in space layout. Artists observe the things with relatively subjective perspective, and are particular about "different sceneries in different situations", so ink painting generally uses cavalier perspective. In the presentation of more large-scale scenes, such as the mountains, the painters often like to observe everything from the perspective of "the heaven" to achieve the state of the harmony between heaven and man, or "to see the origin of all things on earth with heart and view all the scenery of mountains and rivers." The picture often is magnificent and splendid. Secondly, influenced by Taoist philosophy, ink painting also stresses "opposite" and "unity" in space layout, for ancient people believed that all creations have two attributes, "Yin" and "Yang". They are opposite to each other. Lao Tzu said: "Tao is one and only. It contains two elements, Yin Qi and Yang Qi. The intersection of Yin Qi and Yang Qi forms a special atmosphere, in which generate all things in the world. All creations face Yang and turn back to Yin, and form new harmonious bodies in the mixture of Yin Qi and Yang Qi." It shows that all things in the world are of same origin. So, ink painting stresses that changeable spaces should be flowing, harmonious with continuous "Qi".

One major characteristic of Chinese ink painting is blank. In ink painting, there is saying of "using white as blank", for blank is also one part of the whole. White is as deficiency and black is as excess. The combination of deficiency and excess brings a harmonious rhythm. Painter of the Qing Dynasty Da Chongguang (1623 1692) said: "the combination of deficiency and excess creates beautiful artistic conception [18]." In the Ode to Painting, Gao Ripu also said: "there is the operation of "Qi" in the areas without ink[19]." In ink painting the area without ink also has connotation and "Qi" because of 
the setting off of ink. The combination of deficiency and excess creates a beautiful artistic conception, so in Chinese ink painting there is no painted clouds and the blank areas become endless cloud sea; no painted water but the blank areas are expansive water; no painted sky but the areas with flying birds are infinite sky... The contrast of blank and ink mark makes ink more noticeable, for it highlights the subject. Meanwhile, blank extends the space of the picture, and makes artistic image deeper. It can arouse viewers' imagination, and guide viewers to taste the purpose of the painter. Thus, viewers could exchange with the painter in the spiritual level, and have a strong resonance. In the Painter Ma Yuan's Fishing Alone an old man alone sitting in the bow was fishing "Fig. 4". The rest of the space is blank. The whole picture is full of ethereal atmosphere. The small picture looks like a vast sea in a moment, and feelings of viewers may be unconsciously calm down, like the old man in the picture.

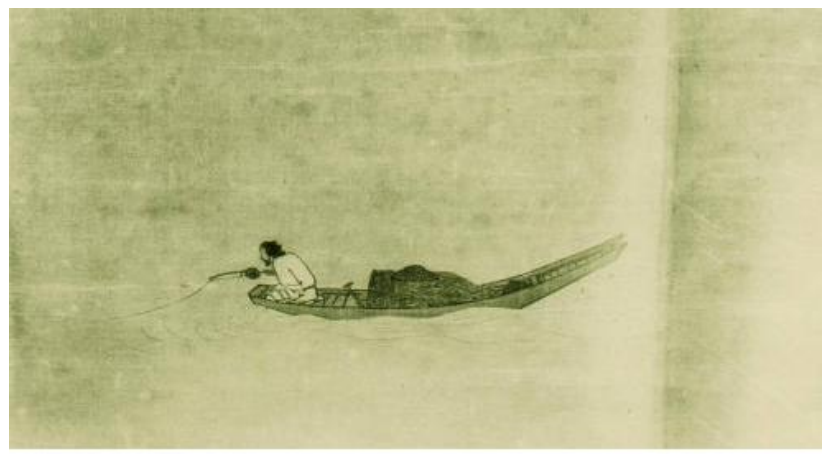

Fig. 4. Fishing Alone

In space layout, the Minimalist art and ink painting are different in approaches but equally satisfactory in results. Minimalist artists not only pay attention to design itself in the creation, and also include the environment in their design. The relationship of their works and the environment is united or opposite. Different from the "opposite" and "united" relationship in Chinese traditional philosophy, the Minimalist artists stress the environment of works, and their final purpose is to care about and reflect works itself and not to show anything outside works. But Chinese ink painting pursues the united and opposite relationship of things in order to achieve the realm of harmonious coexistence. In addition, blank is also an important expression form in Minimalism. There is often a large area of blank in Minimalist art, and viewers could easily catch the focus from the large area of blank - the part the artist wants the viewers to care about, in order to highlight the connotation of the subject and bring more imagination space for viewers.

\section{Artistic Conception}

Both Chinese ink painting and Minimalist art are focused on the creation of artistic conception. Artistic conception is the essence of Chinese ink painting, and the characteristic different from most of Western arts. The artistic conception gives ink painting vitality, endows it with feeling and arouses resonance of viewers. The artistic conception in Chinese ink painting often is given with strong subjective feelings of the painter. Shi Tao of the Qing Dynasty said: "generally artists paint from their heart." Ancient people stressed to paint scenery from feelings and express feelings through scenery. Ink painting is their media to express their ambition and feelings. So, the sceneries and objects in ink painting often are personified. For example, images of plum blossoms, orchid, bamboo and chrysanthemum symbolize noble character of gentlemen. Therefore, the artistic conception of ink painting often exceeds the category of artistic beauty, and rises to the height of philosophy.

Different from our artistic conception creation way, Minimalist artists reject to add any subjective feeling in their works, even not adding a guide element. Marcel Duchamp said: "it is the viewer who creates the painting." It shows that the understanding of viewer is more important than the expression of artist. Minimalist artists prefer to provide an opportunity through the works, so that viewers could have their own understanding according to their thoughts, feelings and psychology. The most unnecessary in enjoying a Minimalist art is to explore the stories behind the works.

Thus, it can be seen that the pursuit of artistic conception in ink painting is different from Minimalist art. The artistic conception in ink painting belongs to the artist, while the artistic conception in Minimalist art is created by viewers.

\section{CONCLUSION}

Chinese ink painting has one thousand years of history. Its techniques and expression forms are unique and of a complete system. It contains deep cultural connotation and miscellaneous knowledge, which cannot be clearly said with these words. The paper only selects the distinct characteristics of ink painting to compare with Minimalist art. But we still can see that the ink painting with thousand years of history has not been abandoned by the times. On contrary, some of its aesthetic tastes and ideas, just like Millennium art, meet the aesthetic needs of modern people.

\section{REFERENCES}

[1] Foreign Art History Teaching and Research Group, Department of Art History, China Central Academy of Fine Arts. Foreign Art Architecture. Higher Education Press, 1990: 330 331.

[2] Yuan Xichang. New Modernism Design. Jiangsu Fine Arts Publishing House, 2001 (8): 200.

[3] Chang Ningsheng. Foreign Post-modern Painting. Jiangsu Fine Arts Publishing House, 2000: 4.

[4] Luo Qikang. Western Art Schools under the Geometrization and Simplification. Exploration of Art, 2005 (2): 59 61.

[5] Li Xiangning. Contemporary European Minimalism Architecture Review (I). Time Architecture, 2000 (2): 50 53.

[6] Fei Jing. Minimalist Painting and Sculpture. World Architecture, 1998 (1): 79 83.

[7] Liu Xiaoming \& Wang Chaozhong. American Landscape Architect Peter Walker and Minimalist Garden. China Garden, 2000, 16 (4): 59 61.

[8] Zhang Junwei: Minimalist Management: Chinese Management Operation System. Machinery Industry Press, 2013.

[9] Li Genyu. A Comparative Study of Chinese and Korean Ink Painting in the 20 Century. Nanjing Arts Institute, 2012.

[10] Yu Jianhua. Collection of China Paintings. Beijing: People's Fine Arts Publishing House, 1986 (12): 592. 
[11] Origin of Words and Phrases. Beijing: the Commercial Press, 1981-12 (the Third Set) 1707.

[12] Shen roujian. Chinese Art Dictionary. Shanghai: Shanghai Dictionary Press, 1987-1: 61

[13] Wei Guangjun. The Origin and Evolution of Chinese Ink Painting. MS Thesis. Chinese Art Research Institute, 2010

[14] Chen Xiaomin. Minimalism in Landscape Design. Yangling: Northwest Agriculture and Forestry University, 2007.

[15] Nielsen J. Ten Usability Heuristics. 2005.

[16] Guo Ruoxu \& Lu Fusheng. Stories of Paintings (Vol. II). 1993.

[17] Du Xirong. Interpretation of Chinese Traditional Humanism. China Literary Federation Press, 2007.

[18] Jing Jianshe. "The combination of deficiency and excess creates beautiful artistic conception" - Art Critic of the Qing Dynasty Da Chongguang. Tricks of Painting: Research of Painting Thoughts. Beauty and Times: Academic (II) 009 (2013): 49 51

[19] Zong Baihua. Aesthetics. Shanghai People's Publishing House, 1981. 